\title{
Getting Healthy by Catching Them All: A Study on the Relationship between Player Orientations and Perceived Health Benefits in an Augmented Reality Game
}

\author{
Jonna Koivisto \\ Gamification Group \\ Tampere University \\ jonna.koivisto@tut.fi \\ Bahadir Gürer Gürkan \\ Gamification Group \\ Tampere University \\ gurkan.bahadir@student.tut.fi
}

\author{
Aqdas Malik \\ Gamification Group \\ Tampere University \\ aqdas.malik@tut.fi \\ Juho Hamari \\ Gamification Group \\ University of Turku \\ juho.hamari@tut.fi
}

\begin{abstract}
In recent years, location-based augmented reality games such as Pokémon Go have become increasingly popular. These games not only afford a novel gaming experience, but also have the potential to alter how players view their physical realities and alter the dynamics of traditional game play from its sedentary nature towards a more physical one. In this paper we investigate what kinds of players (achievement, immersion or social interaction -oriented) are more likely to derive health benefits from playing augmented reality games. We employ online survey data gathered among players of Pokémon Go $(N=1190)$. The results show that playing location-based augmented reality games has a positive association with perceived mental, physical and social health outcomes overall. The results also suggest that the way in which players approach the game and what kinds of aspects of the game they emphasize can have a differential dynamic on how the health benefits of the game manifest. Results show that social gaming orientation is positively associated with physical, mental and social health outcomes, whereas achievement and immersion orientations are associated with physical and mental health outcomes.
\end{abstract}

\section{Introduction}

Augmented Reality (AR) refers to the interactive coexistence of computer generated assets within the physical reality [4]. Such coexistence creates a unique opportunity in video games scenery, especially by altering the traditional way of playing video games. One of the earliest examples of the mobile AR games was ARQuake [76], a Quake-like first person shooter game played with a handheld controller and a head mount display both indoors and outdoors. However, to make this possible, players had to carry around the entire system which weighs approximately $16 \mathrm{~kg}$. As the technology has advanced, AR games have become more mobile which has enabled their commercialization and widespread popularity. Today, we are able to play AR games with the comfort of our smartphones.

One of the most prominent examples of these advancements is Pokémon Go. Launched in the US on July 6 2016, Pokémon Go is a mobile game based on a Japanese transmedia franchise and built on a preexisting mobile game platform by Niantic, Inc. During the first two months of its launch, the game was downloaded more than 500 million times [73]. That year, Pokémon Go won the titles of "best mobile/handheld game", as well as "best family game" [75]. Early statistics by Niantic Labs state that since the launch of the game, Pokémon Go players have collectively walked over 8.7 billion kilometers and caught 88 billion Pokémons [47]. The popularity of Pokémon Go is also evident in the fact that the term "Pokémon Go" was the leading search term in the recently published Google search trends 2016 [17]. Beyond being a Location-Based Game (LBG), Pokémon Go and others like it can also be classified as Augmented Reality Games (ARGs), games that are particularly focused on overlaying digital content onto everyday surroundings. Common to these games and 
activities is that they create hybrid spaces that challenge the dichotomy of the physical and the digital; spaces that "merge the physical and the digital in a social environment created by the mobility of users connected via mobile technology devices" [12].

While there has been a remarkable amount of research on players, player experiences and the gratifications they derive from games (e.g. [10][9][19][20][23][25][26][39][70][68][84]), as well as on player types and orientations [18][31][79][86], LBGs and ARGs are a novel and multifaceted development, not only in the games space, but also culturally. As such they can be seen to afford several kinds of experiences and gratifications for their users that are not necessarily found in more traditional forms of games or media, and especially not in such combinations. These include experiences such as outdoor adventures, communal activities and health benefits. Having recently broken through to a more mainstream audience with the success of Pokémon Go, these games and their players provide a culturally and historically opportune vector for closer study. All of these above-mentioned aspects prompt interesting and relevant research questions in the intersection of gaming and health; can LBGARGs promote healthy behaviors and what kinds of players may be more susceptible to derive these health outcomes.

With this spanning of physical and spatial boundaries in the field of play of LBGs, players are required to move their physical bodies considerable distances in order to play the game. In fact, exercise is not only considered a byproduct of playing LBGs/ARGs, but for many, a chief reason to start playing. For the individual health promotion all the above mentioned game mechanics have been a matter of focus in the domain of serious games studies [16][42]. As noted by O'Hara [49] in Geocaching, the primary motivation for playing was not necessarily achieving the objectives set by the activity, but rather participation in the activity itself. Pokémon Go uses game mechanics and achievements to incentivize walking outdoors and covering relatively long distances. Recent evidence indicate that novel gaming concepts such as Pokémon Go can lead to elevated physical activity [67][30][37]. In the context of the current study, the concept of outdoor activity not only addresses physical activity but also includes other linked activities including meeting friends and engaging in social activities outdoors, as well as visiting and exploring new places.

Therefore, in this study we investigate what kinds of players (achievement, immersion or social orientation) are more likely to perceive health benefits (mental, physical and social health outcomes) from playing augmented reality games. We employ online survey data gathered among players of Pokémon Go $(\mathrm{N}=1190)$.

\section{Background hypotheses}

\subsection{Gamification of health and augmented reality games}

Health is a subject that takes part in every stage of human life starting from birth to old age, and is a basic need for every individual. The main three dimensions of health defined by The World Health Organization are physical, mental, and social well-being [83]. These dimensions are concerned with the physical and mechanical functioning of the body, the ability of thinking clearly and coherently, and the ability to build and maintain relationships [65].

Promotion of health with all its dimensions through game play has gained a lot of attention in the academia (for reviews of the literature, see e.g. [28][5][51][54][62]). Health is in fact one of the most common domains were game design and gameful solutions have been employed (for reviews see [38][21][66]). Gamification refers to design that attempts to transform activities into ones that would afford similar experiences as games do and as such positively affect our motivations and behaviors [27]. As the main inspiration of gamification are games, gamification commonly employs game design mechanics and perspectives to various contexts. Gamification has become the umbrella concept [38] that includes and encompasses, to varying degrees, other related technological veins such as serious games, exergames, augmented-reality games, gamebased learning, games with a purpose, human-based computation games, and persuasive technology, which all slightly vary in their emphases. While augmented reality games, such as Pokémon Go, might have not been intentionally designed to gamefully encourage people to improve their health, it regardless appears to fall into the domain of gamification even though the gamification may not be the main focus of the service.

Since the launch and immense popularity of the Pokémon Go, a sizable amount of research has already been conducted on the solution and its health-related aspects. Looking at the physical health benefits of Pokémon Go, Althoff et al. [1] determined a significant increase in physical activity of Pokémon Go players. Likewise, a number of later studies have confirmed that players are driven to spend time outdoors as the game facilitates socializing with friends, bonding with family members, and creating new social connections [37][30][43][77]. Furthermore, studies have also determined that the salient attributes of the game, 
namely physical activity and social activity, improve mental health and provide support to people with social withdrawal, depression, autism, ADHD, and anxiousness [45][32][37]. In the workplace context, the game has been shown to improve psychological stress of adult workers leading to positive effects on mental health of Japanese workers [82]. Conversely, the game has also been noted to cause serious consequences such as traffic accidents, physical injuries, addictive and obsessive behaviors, and threats to child safety [3][43][56][71][77].

However, what is apparent from the body of related literature is that there remains a dearth of studies that would investigate the relationship between player types and health outcomes. The current body of research has mainly focused on the gratification players derive from playing augmented reality games.

\subsection{Playing orientations}

Within the game research field, there is a substantial vein of research examining and categorizing players based on their play styles, play preferences and orientations regarding play (for a metasynthesis of the research, see [18]. The most prevalent ways of categorizing players in academic research have been their in-game behavior and motivations for playing. One of the earliest models for categorizing players has been Bartle's taxonomy of MUD (Multi-user Dungeon) players [7]. Later on e.g. Yee's [86] works have expanded the focus to e.g. understanding the player motivations of online games. In addition to the behavioral and motivational models, player categorization and segmentation based on demographic and personality factors has also been conducted [18].

The motivation-based taxonomy by Yee [86] has been widely used to understand the rationales of people playing different types of video games [5][61] or using various game-like systems [44]. The taxonomy identifies three different motivational orientations for play: achievement, immersion, and social interaction [86][87]. As indicated by prior research on playing orientations, achievement oriented players seek to experience senses of competence and mastery manifested for example by reaching the top of the high score list or completing the game [86][87]. In the context of Pokémon Go the achievement orientation could manifest as the willingness to "catch them all", that is, to reach high levels within the game. Reaching high levels in the game requires physical activity and moving in one's environment. Consequently, the achievement orientation can be hypothesized to lead to physical health outcomes. Furthermore, satisfying one's achievement needs can also lead to mental satisfaction with one's performance, thus promoting mental health outcomes.

The immersion orientation towards playing commonly manifests as exploration of the game worlds, as a willingness to take the time to get to know storylines and uncover the contents of the game [86][87]. As an augmented reality game that encourages movement within one's own environment, while at the same time augmenting it with the additional layer created by the game and it's rich lore and narrative, Pokémon Go promotes heavily the exploration of one's surroundings and immersing into the content. The exploration is again a physical activity and thus requires being active. Therefore, we hypothesize that the immersion oriented players are also more likely to reach physical health outcomes. Similarly to the achievement orientation, satisfaction of the immersion needs is also considered to lead to mental health outcomes.

Players who are oriented towards social interaction seek to create social connections within the games and experience senses of community and relatedness [86][87]. Similarly to many current game products, Pokémon Go includes strong social elements and has large social communities both within and outside of the game. Potentially due to the popularity and even nostalgia related to the Pokémon franchise, enthusiastic players convene also outside the actual game context to discuss and share experiences regarding the game. Pokémon Go has however been extremely successful in engaging players to be social and create social connections when playing via its design. Game features such as the "lures" that can be bought and activated to increase spawn rates of Pokémons nearby have been reported to be powerful at inducing collaborative and even altruistic behaviors and strongly supporting social interaction in connection to the game play. Thus the game provides extensive opportunities for socially oriented players to satisfy social interaction needs through the game. Thus we hypothesize the social interaction orientation to play Pokémon Go to also lead to increased social health outcomes. Similarly to the other orientations, we also predict the satisfaction of social interaction needs to lead to increased mental health outcomes.

Moreover, as Pokémon Go contains elements which are connected to all of the three health outcomes, physical, mental and social, we expect the amount of playing the game to lead to increased health outcomes on a general level.

In summary, we hypothesize the following:

H1: Achievement orientation is positively associated with physical and mental health outcomes of playing Pokémon Go (or at least more strongly associated than with social health outcomes). 
H2: Immersion orientation is positively associated with physical and mental health outcomes of playing Pokémon Go (or at least more strongly associated than with social health outcomes).

H3: Social interaction orientation is positively associated with social and mental health outcomes of playing Pokémon Go (or at least more strongly associated than with physical outcomes).

H4: Daily playing hours of Pokémon Go are positively associated with the physical, mental and social health outcomes.

\section{Methods and data}

\subsection{Data and participants}

The data was collected via a global online survey open for people who currently play or had recently played Pokémon Go. Launched in the US on July 6 2016, Pokémon Go is a mobile game based on a Japanese transmedia franchise and built on a preexisting mobile game platform by Niantic, Inc. Starting as a GameBoy game in 1995, Pokémon has become a global cultural phenomenon with various video games, anime series, card games, and films. All these media assets have led to a grounded fan-base, that made it possible for the PG game to receive 65 million monthly active users only after 9 months of its release [74].
The survey was initially published on a number of gaming research mailing lists, as well as on the Twitter profiles of the authors. In the brief description text, we requested the readers to post links to the survey on relevant forums. During one month, the survey was tweeted by a number of gaming professionals, academics and research groups. Furthermore, the survey was posted on a number of Pokémon Go Facebook fan pages and by groups notably in the Philippines, Finland, USA, Canada and Australia.

Participation in the survey was completely voluntary and users were afforded the possibility to withdraw at any time. All of the questions in the survey were mandatory. During the one-month period (910/2016), 1315 respondents completed the survey. Out of these responses, 43 respondents who stated that they did not play Pokémon Go were removed from the usable data set. Based on the guidelines proposed for maintaining data quality [46], in total, 82 responses were excluded due to the following reasons. Participants providing careless responses with no variance between individual answers (e.g. all 1's or all 7's etc.), inconsistent responses to two control questions, and obvious outliers (using boxplots and histograms) were excluded from the data analysis. After the data cleaning process, the final data set for statistical analysis composed of 1190 valid responses. Table 2 reports the demographic and playing related characteristics of the respondents.

Table 2. Respondents descriptives regarding demographic and playing related factors $(\mathrm{N}=1190)$

\begin{tabular}{|c|c|c|c|c|c|c|c|}
\hline Measure & & $\mathbf{N}$ & $\%$ & Measure & & $\mathbf{N}$ & $\%$ \\
\hline \multirow[t]{2}{*}{ Gender } & Male & 698 & 58.7 & Occupation & Working full-time & 550 & 46.2 \\
\hline & Female & 492 & 41.3 & & Student & 401 & 33.7 \\
\hline \multirow[t]{9}{*}{ Age } & Under 15 years & 36 & 3.0 & & Working part-time & 102 & 8.6 \\
\hline & $16-20$ years & 179 & 15.0 & & Unemployed & 98 & 8.2 \\
\hline & 21-25 years & 388 & 32.6 & & Full-time homemaker & 33 & 2.8 \\
\hline & $26-30$ years & 302 & 25.4 & & Retired / Pensioner & 6 & 0.5 \\
\hline & $31-35$ years & 132 & 11.1 & Country of residence & Philippines & 402 & 33.8 \\
\hline & $36-40$ years & 74 & 6.2 & & Finland & 375 & 31.5 \\
\hline & $41-45$ years & 36 & 3.0 & & United States & 93 & 7.8 \\
\hline & $46-50$ years & 25 & 2.1 & & Sweden & 42 & 3.5 \\
\hline & Over 51 years & 18 & 1.5 & & United Kingdom & 42 & 3.5 \\
\hline \multirow[t]{5}{*}{ Education } & College degree & 421 & 35.4 & & Singapore & 41 & 3.4 \\
\hline & University degree & 413 & 34.7 & & Canada & 38 & 3.2 \\
\hline & High school & 240 & 20.2 & & Australia & 36 & 3.0 \\
\hline & Vocational degree & 116 & 9.7 & & Malta & 21 & 1.8 \\
\hline & & & & & Others & 100 & 8.4 \\
\hline \multicolumn{8}{|c|}{ Average Pokémon Go play hours/typical day } \\
\hline & $<15$ minutes & 88 & 7.4 & & $2-3$ hours & 140 & 11.8 \\
\hline & $16-30$ minutes & 149 & 12.5 & & 3-4 hours & 101 & 8.5 \\
\hline & $31-45$ minutes & 125 & 10.5 & & 4-5 hours & 45 & 3.8 \\
\hline & 46-60 minutes & 157 & 13.2 & & 5-6 hours & 41 & 3.4 \\
\hline & $1-2$ hours & 279 & 23.4 & & $>6$ hours & 65 & 5.5 \\
\hline
\end{tabular}


Table 3. Convergent and discriminant validity

\begin{tabular}{|c|c|c|c|c|c|c|c|c|c|c|}
\hline & $\begin{array}{l}\text { Average } \\
\text { Variance } \\
\text { Extracted } \\
\text { (AVE) }\end{array}$ & $\begin{array}{l}\text { Composite } \\
\text { Reliability }\end{array}$ & $\begin{array}{c}\text { Cronbach's } \\
\text { Alpha }\end{array}$ & ACHE & IMMER & МH & PH & PMH & SH & SOC \\
\hline ACHE & 0.810 & 0.944 & 0.922 & 0.900 & & & & & & \\
\hline IMMER & 0.781 & 0.934 & 0.907 & 0.574 & 0.883 & & & & & \\
\hline MH & 0.847 & 0.917 & 0.820 & 0.293 & 0.283 & 0.920 & & & & \\
\hline $\mathrm{PH}$ & 0.937 & 0.967 & 0.933 & 0.281 & 0.279 & 0.842 & 0.968 & & & \\
\hline PMH & na & na & na & 0.165 & 0.07 & 0.351 & 0.284 & na & & \\
\hline $\mathrm{SH}$ & 0.702 & 0.943 & 0.929 & 0.284 & 0.276 & 0.769 & 0.734 & 0.315 & 0.838 & \\
\hline SOC & 0.882 & 0.968 & 0.955 & 0.562 & 0.57 & 0.347 & 0.298 & 0.211 & 0.451 & 0.939 \\
\hline \multicolumn{11}{|c|}{$\begin{array}{l}\text { - ACHE = Achievement orientation, IMMER = Immersion orientation, } \mathrm{SOC}=\text { Social interaction orientation, } \mathrm{MH}=\mathrm{Mental} \text { health } \\
\text { outcomes, } \mathrm{PH}=\text { Physical health outcomes, } \mathrm{SH}=\text { Social health outcomes, } \mathrm{PMH}=\text { Average Pokémon Go play hours/typical day } \\
\text { - Square roots of AVEs are reported in bold in the diagonal., na = not applicable, single-item } \\
\text { - Numbers below the diagonal refer to correlations between the constructs }\end{array}$} \\
\hline
\end{tabular}

\subsection{Measurement, validity and reliability}

The playing orientations as well as the health outcomes were measured using previously validated instruments adapted from prior literature. See the Appendix for the constructs and their included items as well as the sources. The independent variables Achievement (ACHE), Immersion (IMMER), and Social Interaction (SOC) included four items each. Of the dependent variables, the physical health outcomes $(\mathrm{PH})$ and the mental health outcomes $(\mathrm{MH})$ included originally 4 items and the social health outcomes $(\mathrm{SH})$ included 7 items. Two items from both $\mathrm{PH}$ and $\mathrm{MH}$ were omitted due to a low loading. All of the variables were measured using a 7-point Likert scale (for independent variables: not at all important - extremely important; for dependent variables: strongly disagree strongly agree).

The model-testing was conducted using the component-based PLS-SEM in SmartPLS 3 [59]. Convergent validity (see Table 3 ) was assessed with two metrics: average variance extracted (AVE) and composite reliability (CR). Convergent validity was met (the AVE of each construct should be $>0.5$, and the CR of each construct should be >0.7: [15]). Discriminant validity was assessed firstly through the comparison of the square root of the AVE of each construct to all of the correlations between it and other constructs (see [15]), where all of the square roots of the AVEs should be greater than any of the correlations between the corresponding construct and another construct [29] (see Table 3). Secondly, we assessed the discriminant validity by confirming that each item had the highest loading with its corresponding construct. From these tests, we can conclude that the discriminant validity and reliability was acceptable. The sample size $(\mathrm{N}=1190)$ also satisfies several different criteria for the lower bounds of sample size for PLS-SEM analysis [2].

\section{Results}

In order to confirm the hypotheses of the study, all of the relationships between the playing orientations and health outcomes as well as the playing time and health outcomes were included in the path model. The path model accounted for $16.7 \%$ of the variance of physical health outcomes, $21.9 \%$ of the variance of mental health outcomes and $25.5 \%$ of the variance of social health outcomes (see Figure 1). The results indicate that the achievement orientation is slightly positively associated with the physical $\left(\beta=.098^{* *}\right)$ and mental $\left(\beta=.080^{*}\right)$ health outcomes, but there is no significant association with the social health outcomes. The immersion orientation is similarly, and more strongly, positively associated with the physical $(\beta=.142 * * *)$ and mental $(\beta=.118 * *)$ health outcomes. The immersion orientation is not associated with the social health outcomes. Interestingly, the social interaction orientation was positively associated with all the health outcomes. The social interaction positively predicts physical $(\beta=.112 * *)$ and mental $(\beta=.172 * * *)$ health outcomes. Understandably, the social interaction is most strongly positively associated with the social health outcomes $(\beta=.371 * * *)$. Furthermore, the estimated daily playing hours of Pokémon Go were used in the model as a control variable. The playing hours were positively associated with all of the outcomes, the physical $(\beta=.234 * * *)$, mental $\left(\beta=.293^{* * *}\right)$ and social $\left(\beta=.232^{* * *}\right)$ health outcomes. We also examined the effect sizes of the health outcomes without the control variable. The effect sizes are reported in Figure 1. 


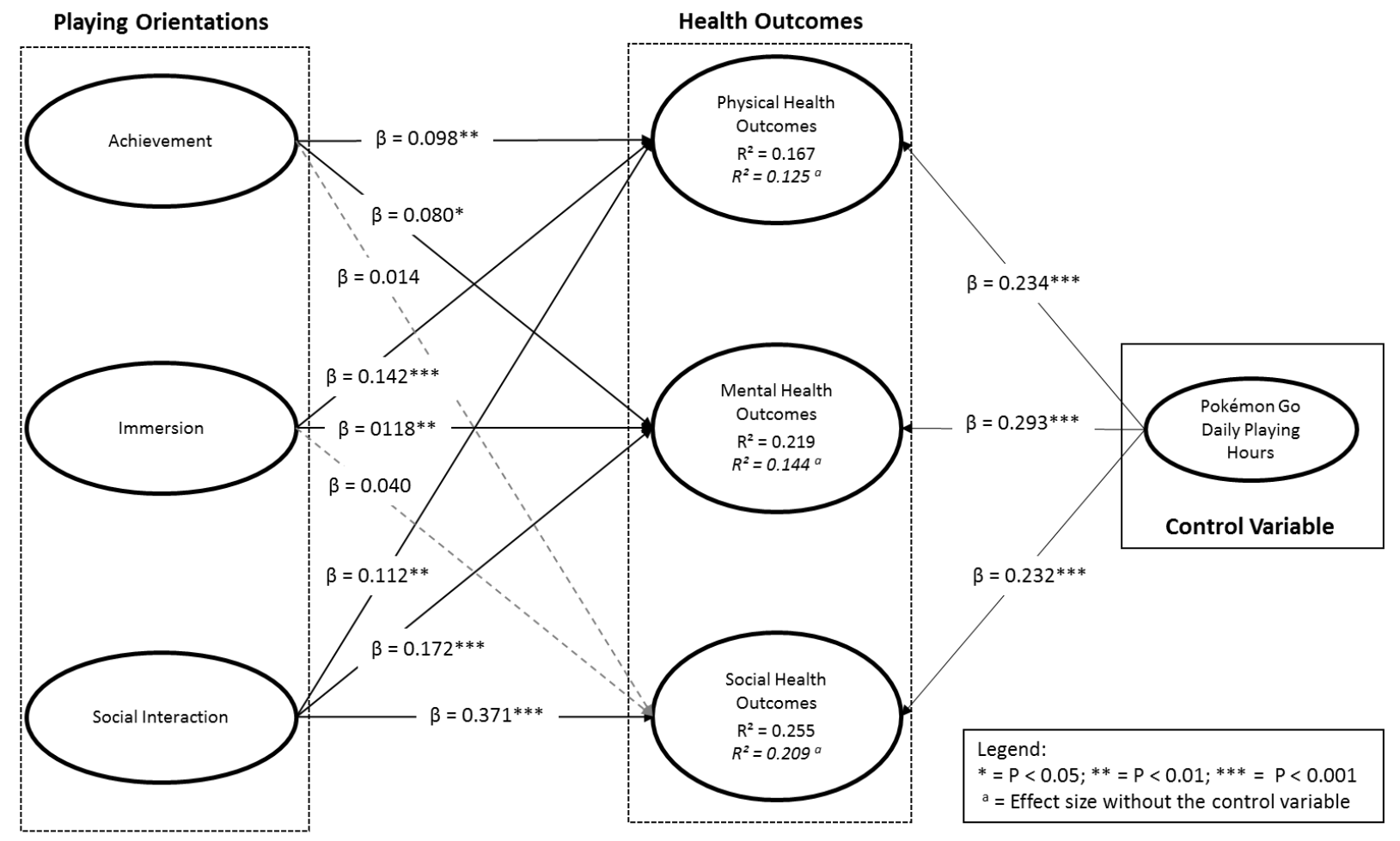

Figure 1. The research model with the results of the analysis

\section{Discussion}

In this study we have investigated the relationship between playing orientations and health outcomes in the context of location-based augmented reality mobile game Pokémon Go. All of the hypotheses were supported by the data. Achievement and immersion orientations were shown to be most strongly positively associated with physical and mental health outcomes from playing Pokémon Go (H1, H2). Social interaction orientation was shown to be associated with all of the health outcomes, however, the strongest associations were expectedly with the social and mental health outcomes, thus supporting the hypothesis (H3). Finally, the daily playing hours of Pokémon Go were shown to be positively associated with all of the physical, mental and social health outcomes (H4). However, it should be noted that model explained between $12.5 \%-25.5 \%$ of the variance of the dependent variables, indicating that there remain many more variables that would explain health outcomes besides playing orientation.

The results of the study suggest that playing location-based augmented reality games can indeed be associated with perceived health benefits. While prior research has mainly focused on one or two types of health in each study (see e.g. [1][37][85][88]), in this study the perspective on health was expanded to include physical, mental and social health. The results of the study indicate that playing the location-based augmented reality games may promote mental and social health benefits in addition to the physical health outcomes. A noteworthy finding regarding the perceived health benefits of the location-based augmented reality games is especially the effect of the amount of playing time to the health outcomes. While the time spent playing the game has a positive association with all of the health outcomes, a considerable increase can be noted especially in the effect size of mental health outcomes due to the time spent playing the game.

Moreover, the results of the study indicate that there are differences in the relationship between the different playing orientations and the dimensions of health; an aspect that has not been examined in prior literature to a sufficient degree. The current study suggests that the ways in which players approach the game and what kinds of aspects of the game they emphasize and thus potentially mostly engage with can have a differential dynamic on how the health benefits of the game manifest. This conclusion was particularly supported by the findings indicating that achievement and immersion oriented players were reporting higher 
perceived physical and mental health benefits and no social health outcomes to a significant degree. Conversely, the socially oriented players reported high perceived social and mental health outcomes, but clearly lower physical health benefits.

Interestingly, the achievement orientation was the weakest predictor of the health outcomes. This finding potentially suggests that the achievement need satisfaction of the players does not translate as directly to health benefits. The stronger associations between the immersion and social interaction orientations and the health outcomes on the contrary seem to indicate that these approaches to the game more directly manifest in the health aspects.

There are some limitations that need to be acknowledged regarding our study. The data has been gathered via an online survey which means the responses are self-reported and the respondents are self-selected, which is common to the given methodology. It has been noted that individuals tend to, for example, over- or underestimate their physical activity when self-reporting [55]. Thus, the potential effects of the data gathering method must be taken into account when evaluation the results. In order to confirm the results of this study based on self-reported data, experimental study designs and use of behavioral data e.g. related to actual physical activity are recommended. With a multi-method approach combining both survey and behavioral data, more accurate understanding of the health benefits of location-based augmented reality games could be gained. Likewise, despite a strong relevance to the game, some of the activity based questionnaire items (e.g. have walked more, have cycled more, have spent more time outdoors, have visited new places) display poor loadings. These results require further investigations preferably by employing log data. Furthermore, it is common in self-reported data that the respondents are likely to be highly engaged users of the service at hand. If this is the case, it potentially leads to the representation of the active users' perceptions in the resultant data. Thus, future studies should seek to include also less active users in order to gain further understanding of the perceptions of that population regarding the service and their reasons for not being actively involved with the service.

\section{Acknowledgements}

This work has been supported by Business Finland (376/31/2018, 5479/31/2017 and 40009/16) and participating partners, Satakunnan korkeakoulusäätiö and its collaborators, Academy of Finland (Center of
Excellence in Game Culture Studies) and National Science Foundation (NSF EEC-1424444).

\section{References}

[1] Althoff, T., R.W. White and E. Horvitz. "Influence of Pokémon GO on physical activity: Study and implications", Journal of Medical Internet Research 18(12), 2016, pp. e315 [2] Anderson, J.C. and D.W. Gerbing. "Structural equation modeling in practice: A review and recommended two-step approach", Psychological bulletin, 103(3), 1988, pp. 411.

[3] Ayers, J. W., E.C. Leas, M. Dredze, J.P. Allem, J.G. Grabowski and L Hill. "Pokémon GO - a new distraction for drivers and pedestrians.", JAMA internal medicine 176(12), 2016, pp. 1865-1866.

[4] Azuma, R., Y. Baillot, R. Behringer, S. Feiner, S. Julier and B. MacIntyre. "Recent advances in augmented reality.", IEEE computer graphics and applications 21(6), 2001, pp. 34-47.

[5] Baranowski, T., R. Buday, D.I. Thompson and J. Baranowski. "Playing for real: video games and stories for health-related behavior change.", American journal of preventive medicine 34(1), 2008, pp- 74-82.

[6] Barnett, A., E. Cerin and T. Baranowski, "Active video games for youth: a systematic review.", Journal of Physical Activity and Health 8(5), 2011, pp. 724-737.

[7] Bartle, R., "Hearts, clubs, diamonds, spades: Players who suit MUDs.", Journal of MUD research 1(1), 1996, pp. 19.

[8] Biddiss, E. and J. Irwin, "Active video games to promote physical activity in children and youth: a systematic review.", Archives of pediatrics \& adolescent medicine 164(7), 2010, pp. 664-672.

[9] Chen, C. and L. Leung. "Are you addicted to Candy Crush Saga? An exploratory study linking psychological factors to mobile social game addiction.", Telematics and Informatics, 33(4),(2016), pp. 1155-1166.

[10] Chen, V. H.-H., H. B.-L. Duh, P. S. K. Phuah and D. Z. Y. Lam. "Enjoyment or engagement? role of social interaction in playing massively multiplayer online roleplaying games (MMORPGS).", In: International Conference on Entertainment Computing, Springer, 2006, pp. 262-267.

[11] Chin, W.W., B.L. Marcolin and P.R. Newsted, "A partial least squares latent variable modeling approach for measuring interaction effects: Results from a Monte Carlo simulation study and an electronic-mail emotion/adoption study.", Information systems research 14(2), 2003, pp. 189217.

[12] De Souza e Silva, A. "Pokémon Go as an HRG: Mobility, sociability, and surveillance in hybrid spaces.", Mobile Media \& Communication 5(1), 2017, pp. 20-23.

[13] Dias, M. and L. Agante. "Can advergames boost children's healthier eating habits? A comparison between healthy and non-healthy food.", Journal of Consumer Behaviour, 10(3), 2011, pp. 152-160.

[14] Djaouti, D., J. Alvarez, J.-P. Jessel and O. Rampnoux. "Origins of serious games.", Serious games and edutainment applications, 2011, pp. 25-43.

[15] Fornell, C. and D.F. Larcker. "Evaluating structural equation models with unobservable variables and 
measurement error.”, Journal of Marketing Research 18(1), 1981, pp. 39-50.

[16] Fuchslocher, A., J. Niesenhaus and N. Krämer. "Serious games for health: An empirical study of the game "Balance" for teenagers with diabetes mellitus.", Entertainment Computing, 2(2), 2011, pp. 97-101.

[17] Google Trends, "Google's Year in Search", Google, 2016. Retrieved from https://trends.google.com/trends/yis/2016/GLOBAL/

[18] Hamari, J. and J. Tuunanen. "Player types: A metasynthesis.", Transactions of the Digital Games Research Association 1(2), 2014.

[19] Hamari, J. and L. Keronen. "Why do people play games? A meta-analysis.", International Journal of Information Management 37(3), 2017, pp. 125-141.

[20] Hamari, J. and M. Sjöblom. "What is eSports and why do people watch it?.", Internet research 27(2), 2017, pp. 211 232.

[21] Hamari, J., J. Koivisto and H. Sarsa. "Does gamification work?--a literature review of empirical studies on gamification.",In: Proceedings of the 47th Hawaii International Conference on System Sciences (HICSS), Hawaii, USA, 2014, pp. 3025-3034.

[22] Henseler, J., C.M. Ringle and M. Sarstedt, "A New Criterion for Assessing Discriminant Validity in Variancebased Structural Equation Modeling.", Journal of the Academy of Marketing Science 43(1), 2015, pp. 115-135.

[23] Hou, J. "Uses and gratifications of social games: Blending social networking and game play.", First Monday 16(7), 2011.

[24] House, J.S., K.R. Landis and D. Umberson. "Social relationships and health.", Science 241(4865), 1988, pp. 540545.

[25] Hsu, C.-L. and H.-P. Lu. "Why do people play on-line games? An extended TAM with social influences and flow experience.", Information \& management 41(7), 2004, pp. 853-868.

[26] Huang, L.-Y. and Y.-J. Hsieh. "Predicting online game loyalty based on need gratification and experiential motives.", Internet Research 21(5), 2011, pp. 581-598.

[27] Huotari, K. and J. Hamari. "A definition for gamification: anchoring gamification in the service marketing literature.", Electronic Markets 27(1), 2017, pp. 21-31.

[28] Johnson, D., et al. "Gamification for health and wellbeing: A systematic review of the literature.", Internet Interventions 6, 2016, pp. 89-106

[29] Jöreskog, K. G. and D. Sörbom. "LISREL 8 user's reference guide", Scientific Software, 1996.

[30] Kaczmarek, L.D., M. Misiak, M. Behnke, M. Dziekan and P. Guzik. "The Pikachu effect: Social and health gaming motivations lead to greater benefits of Pokémon GO use.", Computers in Human Behavior 75, 2017, pp. 356-363.

[31] Kallio, K. P., F. Mäyrä and K.Kaipainen. "At least nine ways to play: Approaching gamer mentalities.", Games and Culture 6(4), 2011, pp. 327-353.

[32] Kato, T.A., A.R. Teo, M. Tateno, M. Watabe, H. Kubo and S. Kanba. "Can Pokémon GO rescue shut-ins (hikikomori) from their isolated world?.", Psychiatry and clinical neurosciences 71(1), 2017, pp. 75-76.
[33] Khalis, A., and A. Y. Mikami. "Who's Gotta Catch'Em All?: Individual differences in Pokèmon Go gameplay behaviors.", Personality and Individual Differences 124, 2018, 35-38.

[34] Kiecolt-Glaser, J.K., L. McGuire, T.F. Robles and R. Glaser. "Emotions, morbidity, and mortality: new perspectives from psychoneuroimmunology.", Annual review of psychology 53(1), 2002, pp. 83-107.

[35] Kim, Y. and S. D. Ross. "An exploration of motives in sport video gaming.", International Journal of Sports Marketing and Sponsorship 8(1), 2006, pp. 28-40.

[36] King, S. "The interactive indulgence: The use of advergames to curb childhood obesity.", Elon Journal of Undergraduate Research in Communications 3(2), 2012.

[37] Kogan, L., P. Hellyer, C. Duncan and R. SchoenfeldTacher. "A pilot investigation of the physical and psychological benefits of playing Pokémon GO for dog owners.", Computers in Human Behavior 76, 2017, pp. 431437.

[38] Koivisto, J. and J. Hamari. "The rise of the motivational information systems: A review of gamification research". A working paper.

[39] Korkeila, H. and J. Hamari. "The Relationship Between Player's Gaming Orientation and Avatar's Capital: a Study in Final Fantasy XIV." In: Proceedings of the 51st Hawaii International Conference on System Sciences, Hawaii, USA, 2018.

[40] Lahtinen, E., V. Lehtinen, E. Riikonen and J. Ahonen (Eds.). Framework for promoting mental health in Europe, Stakes, Hamina, 1999.

[41] LeBlanc, A.G., et al. "Active video games and health indicators in children and youth: a systematic review.", PLoS One 8(6), 2013, e65351.

[42] Lieberman, D.A. "Management of chronic pediatric diseases with interactive health games: Theory and research findings.", The Journal of ambulatory care management 24(1), 2001, pp. 26-38.

[43] Lindqvist, A.-K., D. Castelli, J. Hallberg and S. Rutberg. "The Praise and Price of Pokémon GO: A Qualitative Study of Children's and Parents' Experiences.", JMIR serious games 6(1), 2018, e1.

[44] Lowry, P.B., J. Gaskin, N. Twyman, B. Hammer and T. Roberts. "Taking 'fun and games' seriously: Proposing the hedonic-motivation system adoption model (HMSAM)." , 2012. Retrieved from https://papers.ssrn.com/abstract=2177442

[45] McCartney, M. "Margaret McCartney: game on for Pokémon GO.", BMJ 354, 2016, i4306.

[46] Meade, A. W. and S. B. Craig. "Identifying careless responses in survey data.", Psychological methods 17(3), 2012, pp. 437.

[47] Niantic Labs. Pokémon Go, 2016.

[48] Nishiwaki, M., A. Kuriyama, Y. Ikegami, N. Nakashima and N. Matsumoto N. "A pilot crossover study: effects of an intervention using an activity monitor with computerized game functions on physical activity and body composition.", Journal of physiological anthropology 33(1), 2014, pp. 35.

[49] O'Hara, K. "Understanding geocaching practices and motivations.", In: Proceedings of the SIGCHI Conference on Human Factors in Computing Systems, ACM, 2008, pp. 1177-1186. 
[50] Okan, Z. "Edutainment: is learning at risk?.", British Journal of Educational Technology 34(3), 2003, pp. 255-264. [51] Papastergiou, M. "Exploring the potential of computer and video games for health and physical education: A literature review.", Computers \& Education 53(3), 2009, pp. 603-622.

[52] Parisod, H. et al. "Promoting children's health with digital games: A review of reviews.", GAMES FOR HEALTH: Research, Development, and Clinical Applications 3(3), 2014, pp. 145-156.

[53] Pearson, D.G. and T. Craig. "The great outdoors? Exploring the mental health benefits of natural environments.", Frontiers in psychology 5, 2014, pp. 1178.

[54] Primack, B. A., et al. "Role of video games in improving health-related outcomes: a systematic review.", American journal of preventive medicine 42(6), 2012, pp. 630-638.

[55] Prince, S. A., K. B. Adamo, M. E. Hamel, J. Hardt, S. C. Gorber and M. Tremblay. "A comparison of direct versus self-report measures for assessing physical activity in adults: a systematic review.", The International Journal of Behavioral Nutrition and Physical Activity 5(56), 2008.

[56] Raj, M. A., A. Karlin and Z. K. Backstrom. "Pokémon GO: imaginary creatures, tangible risks.", Clinical pediatrics 55(13), 2016, pp. 1195-1196.

[57] Rauschnabel, P. A., A. Rossmann and M. C. tom Dieck. "An adoption framework for mobile augmented reality games: The case of Pokémon Go.", Computers in Human Behavior 76, 2017, pp. 276-286.

[58] Reiner, M., C. Niermann, D. Jekauc and A. Woll. "Long-term health benefits of physical activity-a systematic review of longitudinal studies.", BMC public health 13(1), 2013, pp. 813.

[59] Ringle, C. M., S. Wende, and S. Will. "SmartPLS 2.0 (M3) Beta, Hamburg 2005.", 2005.

[60] Ruiz-Ariza, A., R.A. Casuso, S. Suarez-Manzano and E.J. Martínez-López. "Effect of augmented reality game Pokémon GO on cognitive performance and emotional intelligence in adolescent young.", Computers \& Education 116, 2018, pp. 49-63.

[61] Ryan, R.M., C.S. Rigby and A. Przybylski. "The motivational pull of video games: A self-determination theory approach.", Motivation and emotion 30(4), 2006, pp. 344-360.

[62] Sardi, L., A. Idri and J. L. Fernández-Alemán. "A systematic review of gamification in e-health.", Journal of biomedical informatics 71. 2017, pp. 31-48.

[63] Sawyer, B. "Serious games: Broadening games impact beyond entertainment.", Computer Graphics Forum 26(3), 2007, pp. xviii-xviii.

[64] Sawyer, B. (2007). Serious games: Broadening games impact beyond entertainment. Computer Graphics Forum, 26(3), xviii-xviii.

[65] Scriven, A. Promoting Health: A Practical Guide, Elsevier Health Sciences, 2017.

[66] Seaborn, K. and D. I. Fels. "Gamification in theory and action: A survey.", International Journal of human-computer studies 74, 2015, 14-31.

[67] Serino, M., K. Cordrey, L. McLaughlin and R.L. Milanaik. "Pokémon Go and augmented virtual reality games: a cautionary commentary for parents and pediatricians.", Current opinion in pediatrics 28(5), 2016, pp. 673-677.

[68] Sherry, J.L., K. Lucas, B.S. Greenberg and K. Lachlan. "Video game uses and gratifications as predictors of use and game preference.", Playing video games: Motives, responses, and consequences 24(1), 2006, pp. 213-224.

[69] Sinclair, J., P. Hingston, M. Masek. "Considerations for the design of exergames." In: Proceedings of the 5th international conference on Computer graphics and interactive techniques in Australia and Southeast Asia. ACM, 2007, pp. 289-295.

[70] Sjöblom, M. and J. Hamari. "Why do people watch others play video games? An empirical study on the motivations of Twitch users.", Computers in Human Behavior 75, 2017, pp. 985-996.

[71] Sobel, K., A. Bhattacharya, A. Hiniker, J.H. Lee, J.A. Kientz and J.C. Yip. "It wasn't really about the Pokémon: Parents' Perspectives on a Location-Based Mobile Game." In: Proceedings of the 2017 CHI Conference on Human Factors in Computing Systems. ACM, 2017.

[72] Sung, H.-T., L. Sigerson and C. Cheng. "Social Capital Accumulation in Location-Based Mobile Game Playing: A Multiple-Process Approach.", Cyberpsychology, Behavior, and Social Networking 20(8), 2017, pp. 486-493.

[73] Takahashi, D. "How Pokémon Go will benefit from Niantic's lessons from Ingress on location-based game design", Venturebeat, 2015. Retrieved from https://venturebeat.com/2015/12/16/how-niantic-will-marryanimated-characters-with-mobile-location-data-in-pokemongo/

[74] Tassi, P. "Believe It Or Not, 'Pokémon GO' Has 65 Million Monthly Active Players", Forbes, 2017. Retrieved from

https://www.forbes.com/sites/insertcoin/2017/04/05/believe-

it-or-not-pokemon-go-has-65-million-monthly-active-

players/\#20b9019a121d

[75] The Game Awards. "The Game Awards 2016 Winners", 2016. Retrieved from http://thegameawards.com/2016/winners/

[76] Thomas, B., et al. "First person indoor/outdoor augmented reality application: ARQuake.", Personal and Ubiquitous Computing 6(1), 2002, pp. 75-86.

[77] Tran, K. M. "Families, resources, and learning around Pokémon Go.", E-Learning and Digital Media 15(3), 2018, pp. 113-127.

[78] Umberson, D., and J. Karas Montez. "Social relationships and health: A flashpoint for health policy.", Journal of health and social behavior 51(1), 2010, pp. S54S66

[79] Vahlo, J., J.K. Kaakinen, S.K. Holm and A. Koponnen. "Digital Game Dynamics Preferences and Player Types.", Journal of Computer-Mediated Communication 22(2), 2017, pp. 88-103.

[80] Wagner-Greene, V.R., A.J. Wotring, T. Castor, J. Kruger, S. Mortemore and J.A. Dake. "Pokémon GO: Healthy or harmful?", American Journal of Public Health 107(1), 2017, pp. 35-36

[81] Warburton, D. E. R, C.W. Nicol and S.S.D. Bredin. "Health benefits of physical activity: the evidence.", Canadian medical association journal 174(6), 2006, pp. 801809. 
[82] Watanabe, K., et al. "Pokémon GO and psychological distress, physical complaints, and work performance among adult workers: a retrospective cohort study.", Scientific reports 7(1), 2017, pp. 10758.

[83] World Health Organization. Constitution of the world health organization, 1995, pp. 47.

[84] Wu, J.-H., S.-C. Wang and H.-H. Tsai. "Falling in love with online games: The uses and gratifications perspective.", Computers in Human Behavior 26(6), 2010, pp. 1862-1871. [85] Yang, C.-c. and D. Liu. "Motives matter: motives for playing Pokémon Go and implications for well-being.", Cyberpsychology, Behavior, and Social Networking 20(1), 2017, pp. 52-57.
[86] Yee, N. "Motivations for play in online games.", CyberPsychology \& behavior 9(6), 2007, pp. 772-775.

[87] Yee, N., N. Ducheneaut and L. Nelson. "Online gaming motivations scale: development and validation.", In: Proceedings of the 2012 ACM annual conference on Human Factors in Computing Systems, Austin, USA, 5-10, May, 2012, pp. 2803-2806.

[88] Zsila, Á., G. Orosz, B. Bőthe, I. Tóth-Király, O. Király, M. Griffiths and Z. Demetrovics. "An empirical study on the motivations underlying augmented reality games: The case of Pokémon Go during and after Pokémon fever.", Personality and Individual Differences, 2017.

\section{Appendix. Full list of employed constructs and their items as well as the sources for the}

constructs.

\begin{tabular}{|c|c|c|c|}
\hline Construct & Items & Loading & Sources \\
\hline \multicolumn{4}{|c|}{ Playing Orientations - "In general, how would you rate the importance of the following aspects in games?" } \\
\hline \multirow[t]{4}{*}{ Achievement } & ACHE1: becoming powerful & 0.863 & \multirow[t]{4}{*}[86]{$[87]$} \\
\hline & ACHE2: winning & 0.899 & \\
\hline & ACHE3: getting the top score/level/points & 0.913 & \\
\hline & ACHE4: being the best & 0.924 & \\
\hline \multirow[t]{4}{*}{ Immersion } & IMMER1: story and theme & 0.882 & \multirow[t]{4}{*}{ [87] } \\
\hline & IMMER2: feeling immersed & 0.859 & \\
\hline & IMMER3: exploring the game-world & 0.905 & \\
\hline & IMMER4: background and history of characters & 0.887 & \\
\hline \multirow[t]{4}{*}{ Social interaction } & SOC1: chatting with other players & 0.925 & \multirow[t]{4}{*}[87]{$[68][35][84]$} \\
\hline & SOC2: keeping in touch with friends & 0.929 & \\
\hline & SOC3: feeling connected to other people & 0.959 & \\
\hline & SOC4: interacting with other players & 0.942 & \\
\hline \multicolumn{4}{|c|}{$\begin{array}{l}\text { Health outcomes- "How much do you agree with the following statements? Since I started playing Pokémon Go, because of the } \\
\text { game I ..." }\end{array}$} \\
\hline \multirow[t]{4}{*}{ Physical health outcomes } & PH1: Feel more energized & 0.969 & \multirow[t]{4}{*}[81]{$[58]$} \\
\hline & PH2: Feel more physically active & 0.967 & \\
\hline & PH3: Have walked/jogged more - omitted & - & \\
\hline & PH4: Have cycled more - omitted & - & \\
\hline \multirow[t]{4}{*}{ Mental health outcomes } & MH1: Feel more mentally active & 0.931 & \multirow[t]{4}{*}[53]{$[40]$} \\
\hline & MH2: Feel less depressed and anxious & 0.910 & \\
\hline & MH3: Spent more time outdoors - omitted & - & \\
\hline & MH4: Visited new places/landmarks - omitted & - & \\
\hline \multirow[t]{7}{*}{ Social health outcomes } & SH1: Have made new friends & 0.839 & \multirow[t]{7}{*}[24]{$[34][78]$} \\
\hline & SH2: Interacted more with my existing friends & 0.838 & \\
\hline & SH3: Interacted more with strangers & 0.800 & \\
\hline & SH4: Interacted more with my family members/relatives & 0.758 & \\
\hline & SH5: Strengthen existing relationships & 0.830 & \\
\hline & SH6: Feel more social & 0.893 & \\
\hline & SH7: Feel more connected with others & 0.899 & \\
\hline
\end{tabular}

